\title{
Students' Personality and Susceptibility to Persuasion during Mathematics Groupwork: An Exploratory Study
}

Jieun Lee (Corresponding author)

Department of Teaching, Curriculum, and Society, Boston College, USA

Email: jieun@bc.edu

Lillie R. Albert

Department of Teaching, Curriculum, and Society, Boston College, USA

Received: 28/07/2021

Accepted: 25/09/2021

Published: 01/11/2021

Volume: 2 Issue: 6

How to cite this paper: Lee, J., \& Albert, L. R. (2021). Students' Personality and Susceptibility to Persuasion during Mathematics Group work: An Exploratory Study. Journal of Practical Studies in Education, 2(6), 10-22

DOI: https://doi.org/10.46809/jpse.v2i6.35

Copyright $\odot$ by author(s) and Global Talent Academy Ltd. This work is licensed under the Creative Commons Attribution International License (CC BY 4.0).

http://creativecommons.org/licenses/by/4.0/

c) (7)

\begin{abstract}
The purpose of this exploratory study was to understand how and to what extent personality traits, positionality, and content knowledge influence students' susceptibility to persuasion during groupwork. Personality surveys, recorded videos, and semistructured interviews provided evidence to support the findings. The findings confirmed that individuals who have low levels of conscientiousness or high levels of neuroticism are more likely to be convinced during a group activity. Additionally, individual background of content knowledge influenced the group persuasion process. A rich body of content knowledge about a subject area helped students feel that they were more confident; those who had confidence were more actively involved in discussions and firmly stood by their own opinions during the social persuasion process. However, the findings indicated there was not a link between susceptibility to persuasion and learners' sociocultural factors. These findings provide educators with insights for improving the design of constructive groups in the mathematics classroom.
\end{abstract}

Keywords: Persuasion, Personality, Content Knowledge, Learning Environment

\section{Introduction}

This exploratory study examines the role of personality traits in shaping one's susceptibility to persuasion during academic groupwork. Susceptibility to persuasion (i.e., persuadability) is the extent to which individuals are willing to change their opinions on a topic (Abebe et al., 2020). "Susceptibility to persuasion (i.e., persuadability) is a phenomenon of the subject who is persuaded, but is influenced by plausibility of the story of which they are persuaded" (Modic et al., 2018, p. 21). The construct of susceptibility to persuasion has been consistently linked to the Big Five Personality Trait Model, and it is widely accepted as the dominant model for examining personality and linking susceptibility to persuasion (Costa \& McCrae, 1992; Wall et al., 2019). During groupwork, students communicate in different ways, including persuasion, ideasharing, organizational interaction, and other methods of communication. However, the consequences of that communication 
vary among students. Some students are predisposed to being persuaded by group members, while others rigorously stand by their own opinions and ideas. There are individual factors that contribute to these differences.

Personality is a critical factor that influences the way a person responds to communication, and it can lead to changes in personal beliefs and attitudes (Janis, 1954). Haugtvedt and Petty (1992) also claims that individual attributes and persuasive communications are highly related factors. Depending on one's personality, some factors (e.g., feeling scared easily) are amenable to social influence, whereas other factors (e.g., tends to be pessimistic) are resistant to such impacts (Wall et al., 2019). This research explores the relationship between one's personality traits and one's susceptibility to persuasion in an academic group setting.

Advocates of interaction analysis view learning as an ongoing social process. Learning is influenced by and inextricably interwoven with social contexts (Nathan \& Sawyer, 2014). An assumption is that understanding how individuals work together may provide evidence that learning is happening or has happened (Jordan \& Henderson, 1995). As such, designing groups to foster effective learning for students is necessary. The membership configuration and interaction style of the groups can create different consequences for individual learning, which means educators need to consider certain elements when arranging students into groups. A general model of group composition suggests that individual characteristics are essential as they are outstanding through group members (Beebe \& Masterson, 2016; Witte \& Davis, 1996). This model implies that individual characteristics are associated with social integration. Therefore, educators should consider students' personalities when creating groups in classrooms to assure greater learning gains. This exploratory study is guided by the following three research questions:

1. How, and to what extent, do students' personality traits influence their susceptibility to persuasion and their capacity to persuade others during groupwork?

2. How, and to what extent, does positionality influence students' susceptibility to persuasion and their capacity to persuade others during groupwork?

3. How, and to what extent, does students' mathematical knowledge mastery influence their susceptibility to persuasion and their capacity to persuade others during groupwork?

The purpose of this study is to examine three factors, including students' personality traits, positionality, and mathematical knowledge mastery, in an effort to determine what factors are salient for students' susceptibility to persuasion during mathematics groupwork. The findings could contribute to a positive mathematics learning environment by providing educators effective ways to arrange students for effective groupwork.

\section{The Conceptual Framework and Related Literature}

\subsection{Big Five Personality Traits Model}

Individuals are influenced by others, and each person has a different level of susceptibility to persuasion. We argue that individual attributes, positionality, and mathematics content knowledge are three factors that can influence one's susceptibility to persuasion during group problem solving. Individual attributes, such as personality, strongly influence numerous human behaviors, including learning and academic performance (Ha \& Kim, 2013). This research uses the Big Five Personality Traits Model by Costa and McCrae (1992) as a conceptual frame to investigate how each trait influences one's susceptibility to persuasion during groupwork. Table 1 lists the Big Five Personality Traits, which are composed of extraversion, agreeableness, conscientiousness, neuroticism, and openness to experience (Donnellan et al., 2006; Costa \& McCrae, 1992).

Table 1. The Big-Five Traits Model Indicator and Its Facet Scales

\begin{tabular}{lll}
\hline \multicolumn{1}{c}{ Domain } & \multicolumn{1}{c}{ Facet } & \\
\hline Extraversion & $\begin{array}{l}\text { Warmth; Gregariousness; Assertiveness; Activity; Excitement-seeking; } \\
\text { Positive; Emotions }\end{array}$ \\
\hline Agreeableness & $\begin{array}{l}\text { Trust; Modesty; Compliance; Altruism; } \\
\text { Tendermindedness }\end{array}$ & Straightforwardness; \\
\hline Conscientiousness & $\begin{array}{l}\text { Competence; Self-discipline; Achievement-striving; Dutifulness; Order; } \\
\text { Deliberation }\end{array}$ \\
\hline Neuroticism & $\begin{array}{l}\text { Anxiety; Hospitality; Depression; Self-consciousness; Impulsiveness; } \\
\text { Vulnerability }\end{array}$ \\
\hline $\begin{array}{l}\text { Openness } \\
\text { to Experience }\end{array}$ & Fantasy; Aesthetics; Feelings; Actions; Ideas; Values & \\
\hline
\end{tabular}

As these five traits are relatively stable over one's lifespan and are largely heritable, psychologists suggest that the BigFive Personality Traits can be used to explain individual behaviors (Ha \& Kim, 2013). Applying the Big-Five Personality Theory Model in this study can help explore the consequences of individual personality traits in group activities, such as behavior in a group and decision making. Accordingly, the Big-Five Traits Model is the most accepted personality model 
(Woods \& Hampson, 2005). For this study, this model also focuses on the individual's positionality and content knowledge that supplement group behaviors. Engagement in sociocultural factors and content knowledge influence group interaction and reflection. Jaramillo (1996) introduces social experiences, such as personal history, culture, and language, to shape the ways through which an individual learns. Based on this concept, this study examines how one's positionality, regarding participants' age, race, and gender, influence behaviors during groupwork. For the purpose of this study, only age, race, and gender were considered. A follow-up study will add more variables, such as students' socio-economic status or educational backgrounds. Academic content knowledge also influencrd students' learning during groupwork and was explored in this paper.

During the reflection stage, individuals may experience persuasive interruptions by others in which they may also intervene with their own views and/or lead to being persuaded. Thus, the following conceptual framework, grounded in the concepts of the Big-Five Traits Model were used to explore the relationships between persuasion in an academic group and an individual's personality, positionality, and mathematics knowledge, as illustrated in Figure 1.

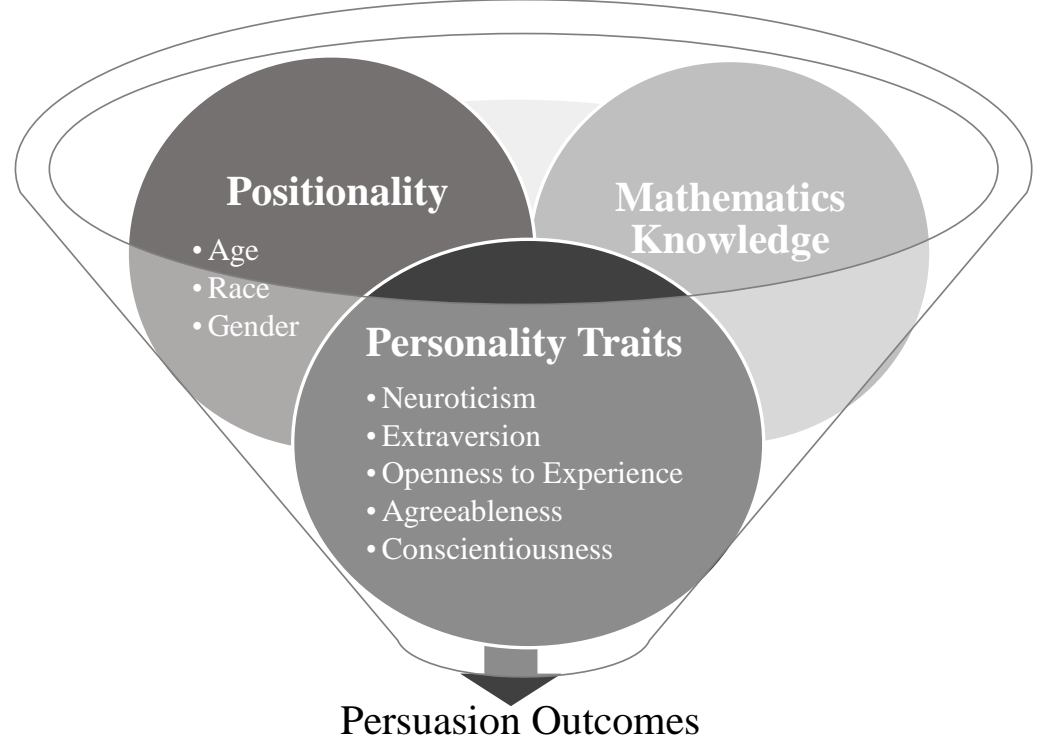

Figure 1. Three Potential Factors That Can Influence One's Susceptibility to Persuasion

\subsection{Sociocultural Group Learning}

For decades, researchers have emphasized the benefits of groupwork in academic settings. Collaborative work offers distinctive features from independent work. Groupwork enables students to exercise the mechanisms of sharing, elaborating, critiquing, explaining, and evaluating shared work (Kapur \& Bielaczyc, 2012). Sawyer (2008) argued that deeper learning starts when students articulate what they have learned, which is a valuable element of groupwork, as students have a chance to articulate their knowledge and share it with others. Vygotsky (1978) contended that the primary driver of intellectual development is social interaction and that thought developed as social interaction is more internalized (Nathan \& Sawyer, 2014). Throughout the cooperative process, a group can achieve collaboration-more than individuals working independently (Stenlund et al., 2017). From a sociocultural perspective, Vygotsky placed value on how individuals construct knowledge in a communicative and interpersonal social setting (Albert, 2012; Jaramillo, 1996). Sociocultural theory research shows that "almost all learning occurs in a complex social environment and that learning is hard to understand if one thinks of it as a mental process occurring within the head of an isolated learner" (Sawyer, 2006, p. 9). A critical element of sociocultural theory is the Zone of Proximal Development (ZPD), which bridges what students already know with what they do not know but can learn with assistance from group members. This mechanism is called scaffolding, in which learners can achieve higher levels of understanding due to accelerated intellectual development compared to working alone (Nathan \& Sawyer, 2014).

Students learn from others through social interaction and scaffolding, but persuasion also occurs during groupwork. Previous studies have introduced several characteristics that impact persuasion for a group member. Janis's (1954) historical research found that individual personality becomes significant when social dialogic interaction takes place. Students' attitudes toward communication vary depending on their nature, leading to reshaping personal beliefs and attitudes. Janis (1954) proposed that people with high self-esteem have fewer tendencies to be influenced by others, whereas people with neurotic anxiety are more stubborn in their opinions. Haugtvedt and Petty (1992) supported the idea that individual attributes and persuasive interactions are highly related. Haugtvedt and Petty (1992) demonstrates that individuals who welcome more cognitive challenges are intrinsically more motivated to meditate and elaborate than individuals who are less open-minded in persuasive contexts. 
Among existing research, there are limited studies that explore how students' personality, positionality, and content knowledge shape the way they are persuaded in an academic group setting. This paper explores susceptibility-to-persuasion in groupwork according to individuals' personality traits, positionality, and mathematical content knowledge. One argument asserts that "the social nature of mathematical communication becomes an integral and substantial part of the learning process. Dynamic mathematical communication is critical to learning and understanding mathematical content and ideas" (Albert, 2000, p.30). The assumption is that operations of a group cannot be understood without examining the individual traits of each member in order to know what each member is bringing to the group. At the same time, understanding the sociocultural context in which the group is functioning is essential. The findings can be used to design an ideal group composition for students so that students can engage and explore their learning in the best social surroundings.

\section{Methodology}

This exploratory study employed both quantitative and qualitative approaches, which include surveys, interviews, video recordings, and written samples of participants' problem-solving work. The analytic procedures were implemented as follows. First, video analysis was based on conversational observation to observe the power of persuasion among peers during the groupwork. Second, using the results of the Big-Five Personality Survey, participants' level of each of the five characteristics was analyzed. This study looked for how and to what extent students' five personality traits are associated with their susceptibility to persuasion in a real mathematics classroom setting. After analyzing the video and survey results, the participants were interviewed about their experience during groupwork, which was used to offer a reason for their actions. Also, participants provided written samples of their problem-solving work. The written samples were used for a better understanding of their behaviors.

The data collection procedures consisted of three phases: video recordings of groupwork, an online survey, and individual interviews. In Phase 1, four graduate students in a graduate-level mathematics problem-solving course self-recorded their collaborative groupwork. The problem-solving process was recorded from the beginning to the completion of the problem. Students worked together and helped each other solve the problems assigned by the course instructor. The problem-solving sessions were designed to provide information about how students learn mathematics and make use of conceptual activities, strategies, and techniques to enhance their learning and understanding of mathematics.

For Phase 2, each participant completed a personality inventory survey to learn about their personality traits. Using the Big-Five Model of Personality Theory, participants took a 20-minute web-based survey. This study used the IPIP-NEO questionnaire to learn about their personality. The IPIP-NEO is an acronym for International Personality Item Pool and is a personality questionnaire based on the Big Five Model: extraversion, agreeableness, conscientiousness, neuroticism, and openness to experience (Costa \& McCrae, 1992). The IPIP-NEO measures the five factors and provides information about one's personality. Goldberg et al. (2006) have granted permission to any individual to use IPIP-NEO measures and the scales are all in the public domain.

During Phase 3, each participant completed a semi-structured interview exploring their groupwork. The in-person interview protocol consists of five demographic questionnaires, eight questions on individual traits, four detailed questions on conflicts during groupwork, and three questions on mathematical understanding.

\subsection{Context and Participants}

The setting for this exploratory study was a mathematical problem-solving course at a private religious affiliated university located in the northeastern region of the U.S. The participants for this study were graduate students enrolled in a mathematical problem-solving course. The group consisted of four female members, ranging in age from 24 to 37 years old. Two have experience in teaching at the elementary level and two at the high school level. Two were international students from South Korea, one participant self-identified as Korean American, and the fourth participant self-identified as a White American. Table 2 presents brief descriptive characteristics of the participants, and all names are pseudonyms.

Margaret is a 37-year-old white female and in the 3rd year of her doctoral program in Curriculum and Instruction with an emphasis in Mathematics Education. Margaret is the only White member in this group. In her career, Margaret has taught for eight years in both Algebra and Geometry classes to students in Grades 8-10.

Hyoju is a 32-year-old Korean female and in the 2nd year of her doctoral program in Curriculum and Instruction. Her undergraduate major was elementary education, and she did her master's in anthropology in South Korea. Hyoju does not have experience as a full-time teacher, but she completed her practicum in a few public elementary schools in her home country in Asia.

Jimin is a 29-year-old Korean female with five years of teaching experience in elementary schools in her home country. She taught many subjects, including mathematics. Her undergraduate major was elementary education, and she completed her master's in the U.S. in the sociology of education. Jimin is in the 1st year of the doctoral program in Curriculum and Instruction.

Yuri is a 24-year-old female and a 5th-year graduate student preparing to teach mathematics at the high school level. She is currently in the Curriculum and Instruction master's program. Her ethnicity is Korean American. Her teaching experiences are limited to being a student teacher, but she has completed three pre-practicum and one full practicum in public and suburban schools. She has taught Algebra 2 and pre-calculus in high school. 
Table 2. Descriptive Characteristic of the Participants

\begin{tabular}{lclllll}
\hline & Age & Gender & Race & Major & $\begin{array}{l}\text { Teaching } \\
\text { Experience }\end{array}$ & Highest Level of Educatior \\
\hline Margaret & 37 & Female & White & $\begin{array}{l}\text { Curriculum \& } \\
\text { Instruction }\end{array}$ & $\begin{array}{l}\text { 8 years in } \\
\text { High School Level }\end{array}$ & $\begin{array}{l}\text { 3rd year } \\
\text { Ph.D. Candidate }\end{array}$ \\
\hline Hyoju & 32 & Female & Asian & $\begin{array}{l}\text { Curriculum \& } \\
\text { Instruction }\end{array}$ & Practicum Only & $\begin{array}{l}\text { 2nd year } \\
\text { Ph.D. Student }\end{array}$ \\
\hline Jimin & 29 & Female & Asian & $\begin{array}{l}\text { Curriculum \& } \\
\text { Instruction }\end{array}$ & $\begin{array}{l}\text { 5 years in } \\
\text { Elementary School } \\
\text { Level }\end{array}$ & $\begin{array}{l}\text { 1st year } \\
\text { Ph.D. Student }\end{array}$ \\
& & & & Aurriculum \& & Practicum Only & Master's Student \\
\hline Yuri & 24 & Female & Asian & $\begin{array}{l}\text { Curruction } \\
\text { Instruction }\end{array}$ & & \\
\hline
\end{tabular}

\subsection{Data Analysis}

As part of the course assignments, participants were required to videotape problem-solving session of non-routine mathematics problems that focus primarily on problem solving processes. ATLAS.ti software was used to code the interpersonal consequences of persuasion within a group interaction. The data was coded both inductively and deductively. Some codes arose directly from their responses, and some were started with a predefined set of codes.

Once participants completed the IPIP-NEO survey, the computer program auto-scored the results, represented as descriptive statistics. The participants received the results of the five personality traits and whether they were situated in a low, average, or high category. The program placed participants' five personality traits into three categories: the lowest $30 \%$ of scores, the middle $40 \%$ of scores, and the highest $30 \%$ of scores. These three categories show where the participants stood with respect to their group members. The program generated these categories based on sex and age. The test results are for understanding individual attributes, and all traits were treated without prejudice (i.e., neither good nor bad). Based on the IPIP-NEO results, Figure 2 illustrates each person's Big-five Personality Traits.

Figure 2. Participants' Big-five Personality Traits ${ }^{1}$

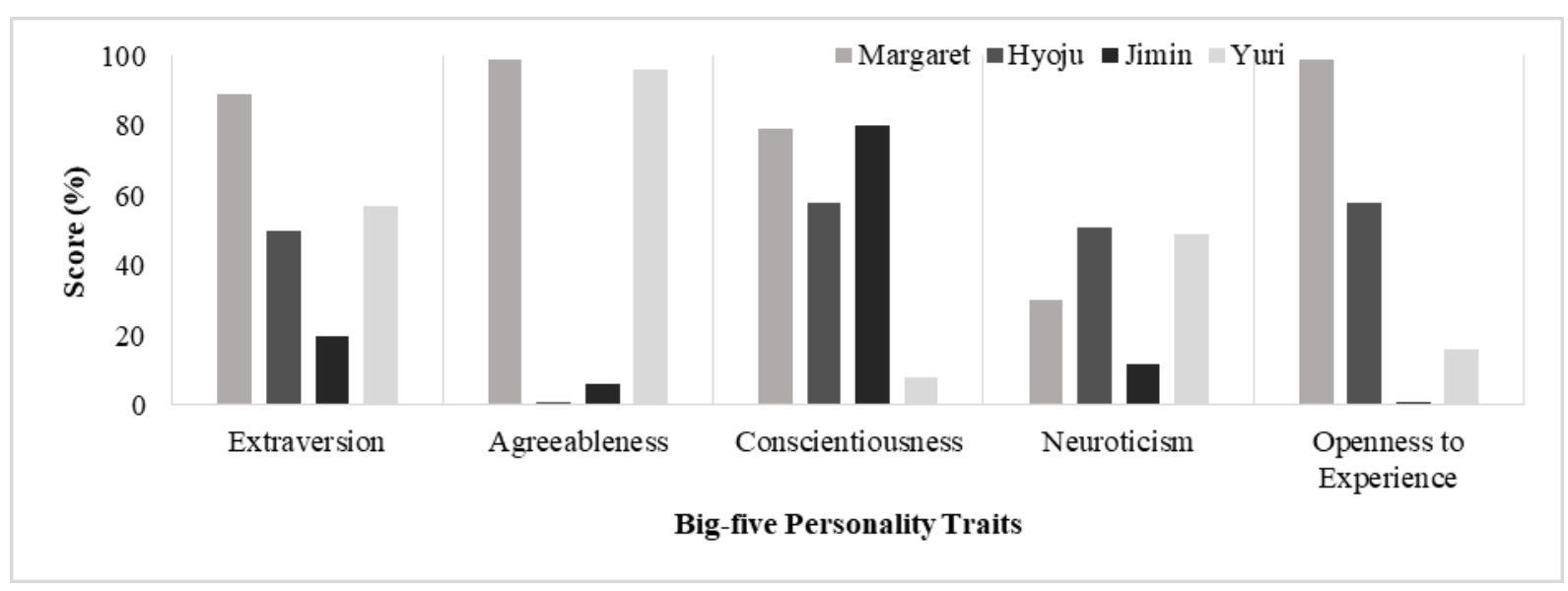

The interviews were audio recorded and transcribed verbatim. Overall, participants provided verbal accounts on engaging their problem-solving tasks, considering their disposition and personality traits. Verbal accounts can be used to understand participants' perspectives about their "experiences or situations as expressed in their own words" (Taylor et al., 2016, p. 102). Interview data were coded through several readings of the transcript, such codes as "persuaded" and "confident." Each theme's properties were integrated through content comparison to identify patterns, connections, and inconsistencies across the participants' interviews. In addition, interview data was analyzed by using inductive and deductive coding to search for new and meaningful perspectives that previous literature might not have found.

A collective frame of the data sources was established with data from videos, surveys, and interviews. To explore the ambiguity of representing the experiences of participants, the data sources offered corroborative evidence to verify information obtained by each method. The use of multiple sources of data, as a form of triangulation, avoided the reliance exclusively on a single data source and thus defused any bias inherent in a particular data (Anfara et al., 2002). 


\section{Findings, Interpretations, and Discussion}

The findings of this research draw from participants' behaviors in the classroom and their personality questionnaire results. Interviews are additional data to support the assumptions and arguments offered in this paper. There were several persuasion cases that happened in the problem-solving video. In this first section, the problem-solving context is presented. The second section consists of the interpretative findings and discussion of the participants' susceptibility to persuasion based on the Big-Five Personality Model results. Then, the participants' individual traits are discussed in relation to the Big-Five Personality Traits. The final section connects participants' gender, race, and age to their positionality. The discussion of participants' use and understanding of their mathematical knowledge is integrated into the findings to illustrate certain aspects or factors of participants' susceptibility to persuasion.

\subsection{The Problem-Solving Context}

The context for this exploratory study was a semester-long, graduate level, mathematical problem-solving course at a private university in the U.S. This course employed an active learning approach to improve students' understanding of teacher preparation in mathematics education, specifically in the learning and teaching of mathematical problem solving. The major areas explored were the nature of mathematical inquiry; models for collaborative grouping; methods, content, and materials for cultivating problem solving, reasoning, and communication processes; methods of assessing mathematical problem solving; and the influence of equity and justice principles. Figure 3 shows the problem statement that participants solved and video-recorded during the problem-solving session.

\section{Figure 3. The Image of the Rectangular Garden Problem}

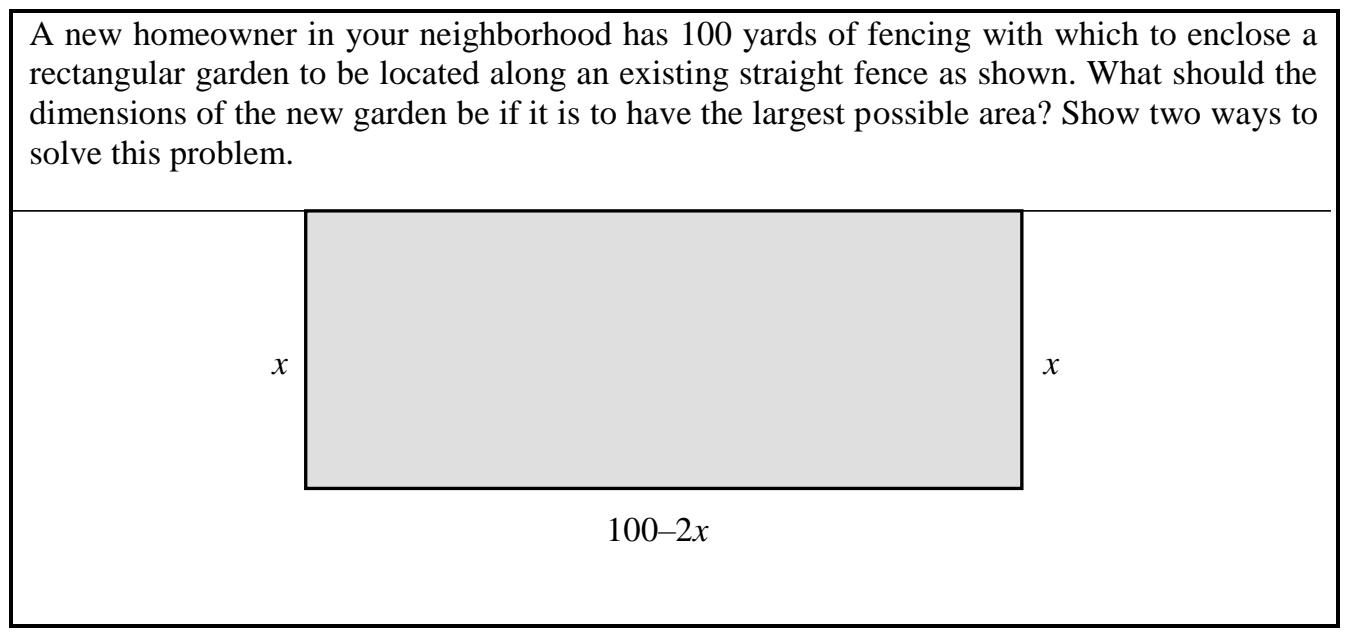

With 100 yards of fencing, students need to figure out what dimensions of a rectangular garden will give the maximum area. The fencing will be used for only three sides, as this garden will be built along an existing fence. In order to address this problem, the participants assigned the value of $x$ to each of two vertical sides, and the value of 100-2x was assigned to the one horizontal side, as portrayed in Figure 3. Also, participants should find the length of each of the three sides to give a maximum garden area, showing more than one method or strategy for solving the problem. For reference, a square is a special type of rectangle, as it possesses all the properties of a rectangle.

4.2. Participants' Susceptibility to Persuasion

For this section and the following sections, an excerpt from the problem-solving video is presented to elucidate findings, such as persuasion failure. For the excerpts, the phrase or sentence italicized illustrates the failure or success of participants' susceptibility to persuasion. Each excerpt includes an interpretation and a discussion.

4.2.1. Persuasion Failure \#1

Yuri: It couldn't be the square.

Jimin, Hyoju: Why?

Yuri: Because it cannot be divided by three. We can't divide hundred by three. Yeah, it's good. Ha-ha.

Margaret: Is it even a square? Isn't it the square we want?

Jimin: What do you mean?

Margaret: I think it has to be a square. But I can't remember why. Right? To get the biggest area.

Jimin: So, this side multiplied by this side. (She changed the topic.) So, $x$ and...right?

This interaction shows the moment of Yuri's failure to convince Margaret. Margaret believes that a square had the largest area of all the quadrilaterals. Yuri insists that the answer should not be a square to get the largest area of this sample quadrilateral (See Figure 3). However, Margaret was not persuaded by Yuri. Margaret continued to believe that the answer should be a square. She seems confident about the concept that she learned somewhere before. Margaret's saying, "I think it has to be a square. But I can't remember why," suggests her inflexible position on this issue. Jimin is another difficult-to- 
convince person. Despite Yuri strongly stressing her idea, Jimin continued to solve the problem in her own way, and she checked whether Yuri's statement was correct or not. During the interview, Jimin said, "Yuri's suggestion did not present clear evidence to support her choice, so I tried to solve it by myself." Compared to Yuri and Hyoju, Margaret and Jimin are difficult to convince.

4.2.2. Persuasion Failure \#2

Hyoju: If $x$ is 26, the area is 1248 , the area becomes smaller. I think 25 gives us the most [largest area].

Margaret: What about $251 / 2$ ?

Jimin: (Checking her work quietly) I have 24, and it also ended up with 1248. (Proving that 24 and 26 have the same results in a smaller number than 25 , which is 1250 ).

When Hyoju tried to persuade Margaret with a new idea, she was not immediately convinced. Margaret questioned the counterexample critically, such as whether Hyoju's new solution could apply to " $251 / 2$." Jimin also was not immediately persuaded. Due to her introverted personality, Jimin did not express her thoughts promptly, but she silently checked the cases that were less than 25. Although Jimin was quiet during portions of the conversation among the group members, it should not be discerned that she was not engaged in the work. Jimin listened to other group members and continued to focus on the problem. "In the context of a small group, even if you remain silent, your nonverbal behavior provides information to others about your emotions and interest, or lack of interest" (Beebe \& Masterson, 2016, p. 3). Jimin finished checking her work, and she confirmed that the cases less than 25 also fit Hyoju's new solution. Then Jimin was finally persuaded by her group member. The analysis of the video interaction showed that Jimin was not easily persuaded; she needed clear evidence to nudge her along. It is also noted that unlike Yuri and Hyoju, Margaret and Jimin were difficult to convince.

4.2.3. Persuasion Success \#1

Yuri: It couldn't be a square.

Hyoju: I don't know why it should be a square, but I learned that from my K-12 experience. It should be a square.

Yuri: The square has the biggest area. Let's look it up, Google.

As the preceding excerpt indicates, Yuri asserted in an earlier conversation that the solution should not be a square to get the largest area. However, influenced by other members' ideas that "a square has the largest area," she was connived to change her own idea, agreeing that the square has the biggest area. Although it appears that Yuri was easily persuaded, persuasive communication or interaction, argued Perloff (2020), is a complex human activity.

4.2.4. Persuasion Success \#2

Yuri: Yeah, the square has the largest area.

Margaret: Yeah, it has to be. Because it can't get a bigger number on each side of that parameter.

Jimin: Oh actually, wait, I got a different idea. I just put the 30 as a maximum. So, 10, 10, 10 each. Then the area is 100 , right? But if we have $6,6,18$. And then 6 multiply by 18 is 104 !

Hyoju: $O h$ !

Margaret: Um... so it doesn't have to be the square... What if we make a drawing? Can somebody draw a calculus graph? When Jimin brought forth a new idea, Hyoju promptly agreed by saying, “Oh!” Hyoju was easily persuaded by Jimin. Unlike Hyoju, Margaret, processing the idea put forth, thought aloud and questioned the argument; then, she suggested that the group try to find a way to justify Jimin's idea. Margaret suggested a calculus approach to find a clear solution to the problem. Also, it is important to highlight here that an essential element that played a part in the participants' ability to influence their group members rested in mathematics content knowledge. Yuri addressed the importance of content knowledge during the interview. She stated,

I think it's pretty important. The more you know, the more resources you have in yourself and you can think about different ways to solve problems. If you don't have content knowledge, you aren't going to know how figure this out? But then again, some of them (problems) are kind of logical, so even if you didn't have specific content knowledge, you can still pull it out from the group members somewhere, so I guess it depends. But I think it's pretty important. (Yuri, personal communication, October 11, 2019)

Then after some thought, Yuri added that even if the person is not confident about specific content knowledge, other group members would have the knowledge. Yuri described the critical value of group collaboration, which is scaffolding, that increases problem-solving performance (Veenman et al., 2006). Jimin had a similar belief on scaffolding: "I am more vulnerable when I think I do not have enough mathematical knowledge for the problem. In that case, I expect help from other group members." According to Jimin, when she thinks that she has less confidence in content knowledge, she is more likely to follow others. Yuri and Jimin suggested that content knowledge plays a significant role when convincing others in a group. In conclusion, as presented in Table 3, it might be challenging to persuade Margaret and Jimin because of their susceptibility to persuasion results, which means that they are difficult to convince. In contrast, Yuri and Hyoju are more susceptible to persuasion, which demonstrates that they are easily persuaded. The latter part of this study will unveil which factors impact students' susceptibility to persuasion in a group. The factors that this paper explored were students' individual personality traits, positionality, and mathematical content knowledge.

4.3. Personality Traits

From the examination of how the participants influenced each other's problem-solving performance during groupwork, another promising development emerged regarding how their personality traits influenced problem-solving performance. This section explores how the Big-Five Traits influenced participants' susceptibility to persuasion during groupwork. 
Table 3. Individual Susceptibility to Persuasion and Classifying the Big-five Data into Three Categories

\begin{tabular}{lllll}
\hline & Margaret & Hyoju & Jimin & Yuri \\
\hline $\begin{array}{l}\text { Susceptibility } \\
\text { to Persuasion }\end{array}$ & Less & Greater & Less & Greater \\
\hline \hline Extraversion & High & Average & Low & Average \\
\hline Agreeableness & High & Low & Low & High \\
\hline Conscientiousness & High & Average & High & Low \\
\hline Neuroticism & Low & Average & Low & Average \\
\hline Openness to Experience & High & Average & Low & Low \\
\hline
\end{tabular}

\subsubsection{Extraversion}

According to Goldberg et al. (2006), extraversion reflects engagement with the external world. People who get high scores on extraversion are extroverts who tend to enjoy being with people, are energetic, and enthusiastic. In opposition, introverted, reserved, and quiet people get low scores on extraversion.

Table 4 presents the number of utterances among group members. Due to groupwork characteristics, the furthermost numbers of utterances were stated aloud to the whole group instead of one-on-one dialogue. Interestingly, the number of utterances matches the extraversion test results. Margaret has the highest number of utterances $(n=42)$, and she scored high on her extraversion test. Hyoju and Yuri had the same number utterances $(n=29)$, yet their score was in the middle or average for the extraversion test. Jimin's score was in the low range for her extraversion test, and she made at least 28 utterances. Webb's (1982) study found similar results about how individual personality influenced students' roles in group interactions. The research claimed that an extroverted person is more likely to participate actively than an introverted person (Webb, 1982).

Table 4. The Number of Utterances Made by Each Group Members

\begin{tabular}{lllllll}
\hline & Margaret & Hyoju & Jimin & Yuri & To Everyone & Total \\
\hline Margaret & $0^{3}$ & 6 & 8 & 18 & 10 & 42 \\
Hyoju & 5 & 0 & 7 & 3 & 14 & 29 \\
\hline Jimin & 10 & 7 & 0 & 3 & 8 & 29 \\
\hline Yuri & 10 & 4 & 1 & 0 & 14 & 126 \\
\hline Total & 25 & 17 & 16 & 24 & 46 & \\
\hline
\end{tabular}

For the participants of this study, the persuasion occurred regardless of their level of extraversion. Margaret, who spoke the most, and Jimin, who spoke the least, are the two people with less susceptibility to persuasion. With triangulated result analysis, there was no clear correlation between extraversion personality and one's susceptibility to persuasion.

4.3.2 Agreeableness

Agreeableness implies the degree to which an individual focuses on collaboration and social harmony. A highly agreeable person values getting along with others. People in this category are friendly, sympathetic, and willing to compromise their interests with others.

Yuri and Margaret received high scores for this trait, while Hyoju and Jimin's scores were low. For example, Yuri often showed her agreeableness during groupwork.

Margaret: What if we take...somebody who may draw calculus? What if we draw it? We can find the maximum.

Yuri: Oh!!!

Yuri showed an active reaction to Margaret when she suggested a new solution. Yuri sympathized with Margaret's point of view. Although Yuri had to recall how to apply a calculus approach to solving the problem, she was the participant in the group who conducted a Google search for a way to solve the problem using calculus. Yuri's active reaction and collaboration in a group showed a high level of agreeableness. Yuri was persuaded by Margaret's new suggestion and started to apply calculus techniques to solve the problem.

Yuri: So negative form, concave... 
Margaret: Down.

Yuri: Which means it is max. Right? Wait, you don't know what $x$ is? I forget how to get it. It's been a while.

Margaret: I know, right?

Margaret is another member who had a high agreeableness score on the test. She is a good listener and is willing to collaborate with others. When Yuri talked to herself while imagining the graph, such as "So negative form, concave...," Margaret assisted her by providing information, saying "Down." Additionally, she synthesized and reacted to what Yuri said, such as "I know, right?" while other group members did not respond.

The results of agreeableness in personality surveys correspond to their actual agreeableness in situated groupwork. Yuri and Margaret had high scores on the agreeableness survey, and they showed high agreeable behaviors during groupwork. However, when considering susceptibility to persuasion, Yuri is easily persuaded while Margaret is not an easy person to be convinced. We argue that agreeableness does not always associate with one's susceptibility to persuasion.

It was also noted that content knowledge matters both in groupwork and to students' susceptibility to persuasion. When Margaret was asked about content knowledge during the interview, she explained the importance of the amount of confidence that students have. When she was asked if she considered herself easy to persuade, she stated, "It would depend on how right I was... or confident about the content." Hyoju also expressed the importance of academic confidence: "If I think my answer is right, I stand by my opinion." The majority of students' academic confidence comes from their content knowledge.

The participants who believed that they had strong content knowledge more actively participated in a groupwork and firmly stood by their own opinions during discussions. Likewise, groupwork is still a good chance for the individual who lacks content knowledge. Those students learned from others and most likely were persuaded by other group members. However, Peeters et al. (2006) argued that when individuals work in group or team settings, the most recognizable traits assisting performance are agreeableness and conscientiousness.

4.3.3. Conscientiousness

Conscientiousness relates to the way of impulse control and self-regulation. A highly conscientious person is organized and requires more time to make a decision, while a less conscientious person shows that they like to do what feels good to them in the moment. Individuals who set clear and pursue goals get higher scores in this category, and individuals who act on their first impulse, who can also be seen as spontaneous and fun-to-be-with, get lower scores in this test. These ideas are evidenced throughout the problem-solving process, especially for Margaret, who stated:

So, is that the maximum? So, each one will be 33 and 1/3. But aren't we convinced it has to be square? I mean,

that's the part I'm not sure [about]. It has to be a square. Right?

Margaret did not draw a hasty conclusion because she may have been persuaded that the answer must be a square. She was searching for clear evidence that the answer should be a square to convince not only everyone in the group but also herself.

Jimin: And if I put 5, 5, 20, it was less than 104. So, there might be some kind of formula...

Margaret: So, what are we doing? So, what is my choice... (draw a table), why do we think it is the largest?

Margaret's utterance shows she was searching for clear evidence to support her idea. Additionally, Margaret tended to plan ahead. Her question, "So, what are we doing?" implies that she wanted to organize the next steps to solve the problem. In the later part of the conversation, she asked Hyoju, "So, are you going to graph up?" which also asks about the plan to organize the group solving process. Margaret is the participant who ended the discussion, suggesting the procedures for writing a report of their problem-solving work. Margaret said, "So now, we just need to make a document." Her behaviors during groupwork, as shown in the video, matched her high scores of conscientiousness. Jimin also searched for clear evidence, and she was reluctant to make impulsive conclusions. She asked, "So, 25 is the largest? (Checking...) Yes, I put 24, and it also ends up as 1248 (which is a smaller number)." Jimin performed several calculations and then confirmed that they were wrong. Jimin's behavior corresponds with her high scores of conscientiousness.

Yuri's performance during groupwork was the opposite of Margaret and Jimin's performances. Yuri had a low score on conscientiousness, and there were several situations during groupwork that illustrated how she acted on her first impulse.

Yuri: You couldn't do a square.

Jimin: Why?

Hyoju: Why?

Yuri: Because it cannot be divided by three. We can't divide hundred by three. Yeah, it's good. Ha-ha.

Yuri started the conversation with an assertive voice, using "couldn't do." Although she had weak evidence to support her point, she spoke very decisively. Unfortunately, other members were not convinced because of Yuri's lack of evidence.

Margaret: Right, it has to be, because see, it's nine. Instead of 100, just for ease. (...)

Yuri: Yeah, the square has the largest area.

When Margaret suggested that the largest possible area has to be square, Yuri agreed hastily without concrete evidence. She again used an assertive voice, saying "has to," and concluded that the square had the largest area.

Likewise, Hyoju had a low score on conscientiousness, and the following conversation shows how she acted impulsively.

Yuri: Maybe, this one is harder than we thought.

Hyoju: How about trying another one (problem)?

Hyoju quickly gave up and suggested another problem set. Hyoju's action is associated with her low conscientiousness. 
Students' conscientious behaviors and their IPIP-NEO personality survey results were well-aligned. The individuals who had low levels of conscientiousness are more likely to be persuaded by others during groupwork. This finding is consistent with a study conducted by Kelsen and Liang (2019). They found that "both Extraversion and Conscientiousness were revealed as partial mediators of Project Work motivation and performance on collaborative oral presentations" (p. 1920). Furthermore, the participants' levels of conscientiousness were associated with their susceptibility to persuasion. The results show that the students with high conscientiousness are less susceptible to persuasion, while low conscientious students are more susceptible to persuasion.

4.3.4. Neuroticism

Neuroticism indicates negative feelings, such as anxiety, anger, or depression. The person who gets high scores at the neuroticism level is likely to react emotionally. On the other hand, the person who scores low in this category is calm or not easily upset.

Less neurotic individuals are less likely to be persuaded. As illustrated earlier in this paper, Margaret and Jimin were not easy to be convinced during the problem solving groupwork, and their low level of neuroticism matched well with their behaviors. When interviewing Margaret, she was asked to describe her personality briefly. She explained, "I try to be thoughtful. And I try to make sure that folks are comfortable with me, and that I am doing things to make other people comfortable." Margaret does not react emotionally. Margaret is relatively rational and good at controlling her emotions. For the same question, Jimin described herself as a patient person; she stated, "I am kind of a calm person and have a huge patience. This is a good thing as a teacher." Jimin thinks her strength lies in her calm personality, especially when educating and guiding students as a teacher. What Margaret and Jimin have in common is that they are less neurotic and hard to be convinced or influenced.

However, Yuri and Hyoju showed negative feelings compared to Margaret and Jimin during the problem-solving groupwork. Yuri stated, "Maybe, this one is harder than we thought," while Hyoju suggested, "How about trying another one (problem)?" Yuri seemed pessimistic when faced with some difficulty while solving the problem. Yuri complained that the problem was difficult. Similarly, once Hyoju faced difficulty solving the question, she was more willing to escape from the challenge instead of putting more effort into it. She acted emotionally when she suggested that the group should give the problem up and try another problem set.

Analysis of video and interview data highlighted that the individuals who had a low level of neuroticism, such as Margaret and Jimin, were less likely to be persuaded by others during groupwork. In contrast, Yuri and Hyoju scored higher in neuroticism compared to Margaret and Jimin, and they were the ones who were influenced more easily.

4.3.5. Openness to Experience

A level of openness to experience helps to distinguish imaginative people from down-to-earth people. The individuals who have high scores on openness to experience tend to be creative, intellectual, artistic, and sensitive to beauty. In other words, the person who has low scores on this category is more likely to be plain, conservative, or have narrow interests, which are indicated in the following excerpt from the problem-solving activity.

Hyoju: How about putting 1 to 15 ? Then figure it out.

Margaret: Are you going to graph up?

Hyoju: Yes, if $x$ is 1 , the result is 98 .

Hyoju received an average score on the openness to experience survey, and her behaviors aligned with this result. Hyoju suggested a new way to find the solution and tried to graph the equation.

Margaret: What if we take... somebody who may [solve it using] calculus? What if we [use calculus] with it? We can find the maximum.

Yuri: Oh!!!

Margaret is also an example of a high-scoring person in openness to experience. She derived new solutions for the question. Margaret's solution was creative compared to the other participants as other group members did not consider it. Unlike Margaret, Jimin, who was also less likely to be persuaded by others, showed behaviors of low openness to experience during the groupwork, and she scored low on openness to experience on the survey. For instance, Jimin announced during the discussion, "And if I put 5, 5, 20, it was less than 104. So, there might be some kind of formula..." Jimin showed down-toearth characteristics. Jimin thinks plainly and tends to follow the standard that is more consonant with mathematical content knowledge.

Instead of suggesting that they should consider solving another problem to fulfill the course assignment, Yuri claimed that "The square has the biggest area. Let's look it up. Google." She went as far as conducting a Google search for the solution to the problem. From her Google search, she found a way to graph the equation $y=100 x-2 x^{2}$, where $x$ is width and $y$ is area. She figured out the maximum area is rectangular. Yuri's behavior matches well with her low score on openness to experience on the survey.

The study showed a relationship between the openness to experience survey results and the participants' actual behaviors. Hyoju and Margaret were more creative and artistic than the other participants, as Jimin and Yuri tended to think simply and straightforwardly about the groupwork problem. However, there is no relationship between the individual's scores on openness to experience and the susceptibility to persuasion.

Overall, analysis of data revealed that for the Big-five Personality Traits, with the exception of the scores for openness to experience, participants' personality traits did influence their performance during problem solving groupwork. 
Koutsombogera and Vogel (2019) found from their research that interaction and the task at hand related to the participants' personality scores at an individual level. This is also the case for the participants of this study.

4.4. Participants' Positionality

Although there are many other areas of positionality for this exploratory study, this section examines the participants' positionality regarding age, race, and gender. Table 5 presents the participants' age, race, and gender in relation to their susceptibility to persuasion.

Table 5. Susceptibility to Persuasion by Age, Race, and Gender

\begin{tabular}{|c|c|c|c|c|}
\hline & Yuri & Jimin & Нyoju & Margaret \\
\hline \multirow{2}{*}{$\begin{array}{c}\text { Age } \\
\text { Susceptibility to Persuasion }\end{array}$} & 24 & 29 & 32 & 37 \\
\hline & Greater & Less & Greater & Less \\
\hline \multirow{2}{*}{$\begin{array}{c}\text { Race } \\
\text { Susceptibility to Persuasion }\end{array}$} & Asian American & Asian & Asian & White \\
\hline & Greater & Less & Greater & Less \\
\hline \multirow{2}{*}{$\begin{array}{c}\text { Gender } \\
\text { Susceptibility to Persuasion }\end{array}$} & Female & Female & Female & Female \\
\hline & Greater & Less & Greater & Less \\
\hline
\end{tabular}

A group consisting of diverse backgrounds can share ideas that the other generation might not think of. The age distribution of the group is 24 to 37 years old. The oldest of the group is Margaret, and the youngest is Yuri. The range between the two is 13 years. Unlike the other two participants who are in their 20s and early 30s, Margaret is the oldest and has more teaching experience than the other three participants. She guided the group as she presented new ideas about how to solve the problem. Margaret also reacted calmly throughout the problem-solving process. For example, when Hyoju stated, "If $x$ is 26, the area is 1248, the area becomes smaller. So, I think 25 gives us the most...," Margaret asked, "What about 25 1/2?" When Hyoju suggested new methods, Margaret was not persuaded. Instead, Margaret reasoned and asked Hyoju to provide justification by using the same equation with other numbers. Age might influence students' ways of thinking or level of mathematics proficiency, as seen in Margaret's case. Although age may have appeared to be an influence in this case, participants' susceptibility to persuasion did not match their positionality in relation to age. Therefore, analysis of data suggests that it is not clear that age impacts one's susceptibility to persuasion.

Race regarding susceptibility to persuasion was also explored for this study. Three of the participants were of Asian descent: Yuri was an Asian American, and two international students were from Asia. During the interview, Yuri expressed her feelings about group composition, stating that she would feel more integrated into the group if the group consisted of all Asians:

I think I definitely feel more comfortable with Asian people, but that's just kind of how I grew up. Ever since middle school, I feel like I've been always hanging out with Asians and most of my close friends were Asians, and I've been living with Asians in college for all four years. Oh, three years, because the first year I didn't live with Asians. I'm also comfortable with Korean too. I made a couple of friends who are in my math classes. They are from Korea. (...) Maybe Asian people, it's just how I assimilate myself. (Yuri, personal communication, October 11, 2019)

Yuri feels comfortable with Asian students when doing collaborative work, which created an agreeable social context for her. Previous studies on ethnic composition examine the differences between homogeneous and heterogeneous groups. Some researchers suggest that an ethnically homogeneous group is more cohesive than a heterogeneous group (Williams \& O'Reilly, 1998). On the other hand, others propose that an ethnically diverse group has a higher quality of creative brainstorming and group efficacy (Sargent \& Sue-Chan, 2001). As such, racial backgrounds may have different influences on groupwork (Paletz et al., 2004). A possible explanation is that when individuals feel comfortable in familiar group surroundings, they may be convinced by their group members more effortlessly. However, this study did not yield data that support the conclusion that race as a factor influences students' susceptibility to persuasion during groupwork.

The group consisted of all female students, as seen in Table 5; therefore, it was difficult to examine how gender influenced the individuals' susceptibility to persuasion in groupwork. Only Yuri mentioned gender during the interview, stating that gender differences during groupwork were insignificant to her. She stated, "I think gender is not a big deal to me. I can't really tell." Since the group consisted of a single gender, analysis of data cannot yield findings about how gender influenced participants' susceptibility to persuasion during groupwork.

In summary, although the four participants had varying degrees of susceptibility to persuasion with respect to age, race, and gender, these factors did not seem to have a major influence on their susceptibility to persuasion during problem-solving groupwork. This may be the case because of the small number of participants, similarly with regards to race and gender. Also, there might have been other positionality factors that influenced behavior during groupwork, such as sociocultural differences, socio-economic status, or level and type of teaching experiences. These are limitations that must be explored in future studies. 


\section{Conclusion}

The results of this study indicate how one's personality traits, positionality, and content knowledge influence one's susceptibility to persuasion during mathematics groupwork. Both the personality inventory and video data provided evidence supporting that those individuals who have a low level of conscientiousness are more likely to be persuaded during groupwork. Additionally, individuals who have a high score on neuroticism are more easily convinced than their counterparts.

Knowing the content is linked to one's confidence, and one's confidence level influences a learner's susceptibility to persuasion during groupwork. Academic confidence comes from strong content knowledge. A rich body of content knowledge about a subject area helped students feel that they were more confident; those who had confidence were more actively participated in discussions and firmly stood by their own opinions during the social persuasion process. Therefore, participants' content knowledge is associated with susceptibility to persuasion during groupwork.

Sociocultural factors, such as age, race, and gender, influence learners' group selection or proficiency. However, the study did not find strong evidence of how those factors influence learners' susceptibility to persuasion during groupwork. This may be the case because of the small number of participants. They came from similar sociocultural backgrounds and were of the same gender. Although this study's findings are not generalizable to larger similar populations, this study found that levels of conscientiousness, neuroticism, and content knowledge are associated with susceptibility to persuasion during groupwork for the participants of this study. Based on the findings, it is suggested that educators and their preparation programs consider these findings, such as learners' personality traits when assigning them to and designing ideal group composition in the classroom, thereby learners can engage and explore their learning in the most productive social surroundings.

\section{Limitations and Future Directions}

One limitation of this exploratory study is that this study was restricted to one mathematics problem-solving group from a single institution. This study shows how individual conscientiousness, neuroticism levels, and content knowledge impact students' persuasion outcomes in mathematics groupwork. However, if the researchers could replicate the analyses on a larger scale, the generalizability of these findings may be enhanced.

The second limitation of this paper is the lack of gender diversity of the group. Teachers are predominantly female and so are a significant proportion of student teachers. In this study, all participants were females. The research validity could be increased if the study recruits male participants and observes how individual gender positionality works in susceptibility to persuasion during groupwork. Thus, organizing a similar research study with a greater number of participants and gender diversity might broaden our understanding of how individual's personality, positionality, and mathematics knowledge influence students' susceptibility to persuasion in a group.

\section{References}

Abebe, R., Chan, T. H., Kleinberg, J., Liang, Z., Parkes, D., Sozio, M., \& Tsourakakis, C. E. (2020). Opinion dynamics with varying susceptibility to persuasion via non-convex local search. arXiv preprint arXiv:2011.02583.

Albert, L. R. (2000). Outside In, Inside Out: Seventh grade students' mathematical thought processes. Educational Studies in Mathematics, 41, 109-142.

Albert, L. R. with D. Corea and V. Macadino (2012). Rhetorical ways of thinking: Vygotskian theory and mathematical problem solving. New York: Springer Publishing Company.

Anfara, V. A., Brown, K. M., \& Mangione, T. L. (2002). Qualitative analysis on stage: Making the research Process more public. Educational Researcher, 31(7), 28-38. https://doi.org/10.3102/0013189X031007028

Beebe, S. A. \& Masterson, J. T. (2016). Communicating in small groups: Principles and practices. Boston, MA: Pearson.

Costa, P. T. \& McCrae, R. R. (1992). Normal personality assessment in clinical practice: The NEO personality inventory. Psychological Assessment, 4(1), 5-13. https://doi.org/10.1037/1040-3590.4.1.5

Donnellan, M. B., Oswald, F. L., Baird, B. M., \& Lucas, R. E. (2006). The mini-IPIP scales: Tiny-yet-effective measures of the Big Five factors of personality. Psychological Assessment, 18, 192-203. https://doi.org/10.1037/10403590.18.2.192

Goldberg, L. R., Johnson, J. A., Eber, H. W., Hogan, R., Ashton, M. C., Cloninger, C. R., \& Gough, H. C. (2006). The international personality item pool and the future of public domain personality measures. Journal of Research in Personality, 40, 84-96. https://doi.org/10.1016/j.jrp.2005.08.007

Ha, S. \& Kim, S. (2013). Personality and subjective well-being: Evidence from South Korea. Social Indicators Research, 111(1), 341-359. https://doi.org/10.1007/s11205-012-0009-9

Haugtvedt, C. P. \& Petty, R. E. (1992). Personality and persuasion: Need for cognition moderates the persistence and resistance of attitude changes. Journal of Personality and Social Psychology, 63(2), 308-319. https://doi.org/10.1037/0022-3514.63.2.308

Janis, I. L. (1954). Personality correlates of susceptibility to persuasion 1. Journal of Personality, 22(4), 504-518. 
https://doi.org/10.1111/j.1467-6494.1954.tb01870.x

Jaramillo, J.A. (1996). Vygotsky's sociocultural theory and contributions to the development of constructivist curricula. Education, 117(1), 133-140.

Jordan, B. \& Henderson, A. (1995). Interaction analysis: Foundations and practice. The Journal of the Learning Sciences, 4(1), 39-103. https://doi.org/10.1207/s15327809j1s0401_2

Kapur, M. \& Bielaczyc, K. (2012). Designing for productive failure. The Journal of the Learning Sciences, 21(1), $45-83$. https://doi.org/10.1080/10508406.2011.591717

Kelsen, B. A. \& Liang, H. (2019). Role of the Big Five Personality Traits and motivation in predicting performance in collaborative presentations. Psychology Report, 122(5), 1907-1924. https://doi.org/10.1177/0033294118795139

Koutsombogera, M. \& Vogel, C. (2019). Observing collaboration in small-group interaction. Multimodal Technologies and Interaction, 3(3). https://doi.org/10.3390/mti3030045

Modic, D., Anderson, R., \& Palomäki, J. (2018). We will make you like our research: The development of a susceptibility-topersuasion scale. PLoS ONE, 13(3), e0194119. https://doi.org/10.1371/journal.pone.0194119

Nathan, M. \& Sawyer, R. (2014). Foundations of the learning sciences. In R. Sawyer (Ed.), The Cambridge handbook of the learning sciences (pp. 21-43). Cambridge: Cambridge University Press. https://doi.org/10.1017/CBO9781139519526.004

Paletz, S. B. F., Peng, K., Erez, M., \& Maslach, C. (2004). Ethnic composition and its differential impact on group processes in diverse teams. Small Group Research, 35(2), 128-157. https://doi.org/10.1177/1046496403258793

Peeters, M. A., Van Tuijl, H. F., Rutte, C. G., \& Reymen, I. M. (2006). Personality and team performance: A meta-analysis. European Journal of Personality, 20(5), 377-396. https://doi.org/10.1002/per.588

Perloff, R.M. (2020). The Dynamics of persuasion: Communication and attitudes in the twenty-first century (7th ed.). Routledge.

Sargent, L. D. \& Sue-Chan, C. (2001). Does diversity affect group efficacy? The intervening role of cohesion and task interdependence. Small Group Research, 32, 426-450. https://doi.org/10.1177/104649640103200403

Sawyer, R. K. (2006). The Cambridge handbook of the learning sciences. Cambridge: Cambridge University Press.

Sawyer, R. K. (2008). Optimizing learning implications of learning sciences research. In OECD, Innovating to learn, learning to innovate, 45, (pp. 35-98). OECD Publishing, Paris, https://doi.org/10.1787/9789264047983-4-en

Stenlund, T., Jönsson, F. U., \& Jonsson, B. (2017). Group discussions and test-enhanced learning: Individual learning outcomes and personality characteristics. Educational Psychology, 37(2), 145-156. https://doi.org/10.1080/01443410.2016.1143087

Taylor, S. J., Bogdan, R., \& DeVault, M. L. (2016). Introduction to qualitative research methods: A guidebook and resource. John Wiley \& Sons, Inc.

Wall, H. J., Campbell, C. C., Kaye, L. K., Levy, A., \& Bhullar, N. (2019). Personality profiles and persuasion: An exploratory study investigating the role of the Big-5, type D personality and the dark triad on susceptibility to persuasion. Personality and Individual Differences, 139, 69-76. https://doi.org/10.1016/j.paid.2018.11.003

Webb, N. M. (1982). Group composition, group interaction, and achievement in cooperative small groups. Journal of Educational Psychology, 74(4), 475. https://doi.org/10.1037/0022-0663.74.4.475

Williams, K. Y. \& O’Reilly, C. A. (1998). Demography and diversity in organizations: A review of 40 years of research. In B. Staw \& R. Sutton (Eds.), Research in organizational behavior, Vol. 20 (pp. 77 - 140). Greenwich, CT: JAI Press.

Witte, E. H. \& Davis, J. H. (Eds.). (1996). Understanding group behavior, 1. Consensual action by small groups. Lawrence Erlbaum Associates, Inc.

Woods, S. A. \& Hampson, S. E. (2005). Measuring the Big Five with single items using a bipolar response scale. European Journal of Personality: Published for the European Association of Personality Psychology, 19(5), 373-390. https://doi.org/10.1002/per.542

Veenman, M. V. J., Van Hout-Wolters, B. H. A. M., \& Afflerbach, P. (2006). Metacognition and learning: Conceptual and methodological considerations. Metacognition and Learning, 1, 3-14. https://doi.org/10.1007/s11409-006-6893-0

Vygotsky, L. S. (1978). Mind in society: The development of higher psychological processes. Cambridge, MA: Harvard University.

\section{Endnotes}

\footnotetext{
${ }^{1}$ The personality trait scores range from 0 to 100 , scores are based on the IPIP-NEO survey.

${ }^{2}$ Susceptibility to Persuasion is not the sum of BIG Five Traits.

${ }^{3} 0=$ participant was not observed engaging in self talk.
} 